\title{
Global nutrition transition and the pandemic of obesity in developing countries
}

\author{
Barry M Popkin, Linda S Adair, and Shu Wen Ng
}

Decades ago, discussion of an impending global pandemic of obesity was thought of as heresy. But in the 1970s, diets began to shift towards increased reliance upon processed foods, increased away-from-home food intake, and increased use of edible oils and sugar-sweetened beverages. Reductions in physical activity and increases in sedentary behavior began to be seen as well. The negative effects of these changes began to be recognized in the early 1990s, primarily in low- and middle-income populations, but they did not become clearly acknowledged until diabetes, hypertension, and obesity began to dominate the globe. Now, rapid increases in the rates of obesity and overweight are widely documented, from urban and rural areas in the poorest countries of sub-Saharan Africa and South Asia to populations in countries with higher income levels. Concurrent rapid shifts in diet and activity are well documented as well. An array of large-scale programmatic and policy measures are being explored in a few countries; however, few countries are engaged in serious efforts to prevent the serious dietary challenges being faced.

(c) 2011 International Life Sciences Institute

\section{INTRODUCTION}

Several decades ago, it was heresy to talk about an impending global pandemic of obesity. However, diets and activity patterns were clearly changing drastically in the United States, and by the 1980s it was understood that dietary quality in the United States was worsening, physical activity was drastically declining, and obesity was rising across the United States and Europe. At that point, only the United States was considered to have an obesity problem, with more than half of adults in some age-, gender-, race-, or ethnic-specific subpopulations being overweight or obese. Home economics was dying as a taught art in US schools, consumption of processed food and prepared meals was increasingly common, eating away from home, particularly in fast food restaurants, was becoming a major part of many people's lives, and concern about a wider array of health conditions related to obesity was increasing. In reviewing the early publications on the nutrition transition published in Nutrition
Reviews, several key themes were found ${ }^{1,2}$ : urbanization was a major driving force in global obesity, and overweight and obesity were emerging in low- and middleincome countries. Changes in edible oil production had created cheap vegetable oils that allowed people in lowand middle-income countries to increase their energy consumption at very low levels of income. ${ }^{1}$ However, at that point in history, it was assumed that global hunger and malnutrition were the dominant concerns in lowand middle-income countries; it was thus very difficult to draw attention to the important roles being played by shifts in diet and physical activity, which were increasing the threat of obesity in these settings.

Over the past several decades, a dramatic shift has occurred, in stages, regarding the way the entire global population eats, drinks, and moves, and these changes have clashed with human biology to create major changes in body composition. The primary mismatches between human biology and modern society that we have identified in our research are highlighted in Table $1 .^{3-12}$ 
Table 1 Technological clashes with human biology.

\begin{tabular}{ll}
\hline Biology & Technology \\
\hline Sweet preferences & $\begin{array}{c}\text { Cheap caloric sweeteners, } \\
\text { food processing benefits } \\
\text { Caloric beverage revolution }\end{array}$ \\
$\begin{array}{c}\text { Thirst and hunger/satiety } \\
\text { mechanisms not linked }\end{array}$ & $\begin{array}{c}\text { Fatty food preference } \\
\text { Edible oil revolution; } \\
\text { high-yield oilseeds; } \\
\text { cheap removal of oils }\end{array}$ \\
Desire to eliminate exertion & $\begin{array}{c}\text { Technology in all phases of } \\
\text { movement/exertion }\end{array}$ \\
\hline
\end{tabular}

Data from references 3-12.

In 2008, overweight and obesity were estimated to afflict nearly 1.5 billion adults worldwide. One estimate, which a recent analysis of new data shows is an underestimate, predicted that in 2030 an estimated 2.16 billion adults worldwide will be overweight and 1.12 billion will be obese..$^{13}$ Below, trends data are provided from repeated surveys conducted over the 1990-2010 period in over 40 countries using the same methods; these data suggest that 2 or more billion people are possibly already overweight or obese today. The implications of these trends for health, quality of life, productivity, and healthcare costs are staggering. The burden is greater for much of Asia, Latin America, the Middle East, and Africa due to differences in fat patterning and body composition and the cardiometabolic effects of body mass index (BMI) at levels far below the standard BMI cutoff of 25 for overweight. ${ }^{14,15}$ For example, these results are seen in India in relation to the prevalence of diabetes and impaired fasting glucose and in China in the prevalence of hypertension and diabetes.

This review documents the changes that have been and are occurring in global obesity and describes what some countries are doing in response; a focus is placed on the potential options being considered by low- and middle-income countries. This review also provides a comprehensive examination of the current state of the science on the diet-related changes occurring in the lowand middle-income countries of the world.

\section{OBESITY IN LOW- AND MIDDLE-INCOME COUNTRIES}

Recent studies have used data from a large number of countries to estimate current prevalence rates and to project increases in obesity in all regions of the world. ${ }^{13,16}$ However, little detailed information exists on longitudinal trends for low- and middle-income countries, aside from Brazil, China, India, and Mexico. ${ }^{17,18}$ In addition, none of the recent studies have focused on withincountry trends related to urban-rural or income/wealth differences. The general impression has been that in higher-income countries greater obesity rates are often found in rural areas and among the poor, which is the reverse of what is seen in lower-income countries. However, new evidence suggests that these patterns are changing, and the increasing rate of obesity among the poor has important implications for the distribution of health inequalities. ${ }^{19}$ In the past three decades, the agestandardized mean BMI, the most widely used metric for defining overweight and obesity, has increased by $0.4-0.5$ kilograms/meter ${ }^{2} /$ year. $^{13}$

The major gaps in this literature relate to lack of data and superficial examinations of patterns and trends without sufficient attention to the extant literature and the dynamics of change, rather than simplistic cross-sectional perspectives. For example, in recent papers, Subramanium et al., ${ }^{16}$ using just one wave of data and ignoring dynamics, point out that the rich are far more likely than the poor to be obese. This is a very different conclusion from that reached by Jones-Smith et al., ${ }^{20,21}$ who use similar data but longitudinal analysis. Jones-Smith et al. studied repeated cross-sectional data from women between the ages of 18 and 49 years in 37 developing countries to assess withincountry trends in overweight/obesity inequalities by socioeconomic status (SES) between 1989 and 2007 $(n=405,550)$. Meta-regression was used to examine the associations between gross domestic product (GDP) and disproportionate increases in overweight prevalence by SES with additional testing for modification by countrylevel income inequality. In 27 of 37 countries, higher SES (versus lower) was associated with higher gains in overweight prevalence; in the remaining 10 countries, lower SES (versus higher) was associated with higher gains in overweight prevalence. GDP was positively related to a faster increase in overweight prevalence among the lower wealth groups. Among countries with a higher GDP, lower income inequality was associated with faster growth in overweight prevalence among the poor.

Another limitation of current research is the focus on women of childbearing age and preschoolers. This reflects the availability of data from multiple countries that have relied on demographic and health surveys, which focus on women of childbearing age and their children. A few studies, particularly some national surveys from Mexico and Brazil and a few large-scale longitudinal studies including the China Health and Nutrition Survey, the Indonesia Family Life Survey, and the Mexico Family Life Survey, cover all age and gender groups. ${ }^{19}$ Using inclusive data, one sees quite different gender-specific patterns of change and differentials by SES. According to the limited research and data available, men with higher SES have higher rates of overweight and obesity than men with lower SES. ${ }^{22}$ These figures for men contrast with the trends found among women as highlighted by the two Jones-Smith et al. papers described above. ${ }^{20,21}$ 
While we know obesity prevalence appears to be rising across all low- and middle-income countries, it is not clear what urban-rural difference may exist. This review brings together some comprehensive data that were recently published elsewhere. ${ }^{19,20}$ These data are from repeated nationally representative cross-sectional surveys of 441,916 rural and 364,267 urban (806,183 total) adult women (18-49 years old) from 42 countries in Asia, the Middle East, Africa (East, West, central, and southern), and Latin America. The absolute and relative changes in prevalence of overweight and obesity for women in these countries and regions are shown in the supporting information for this article available online as Table S1. The combined prevalence of overweight and obesity $\quad$ (overweight $=\mathrm{BMI} \geq 25$, obesity $=\mathrm{BMI} \geq 30$; called overweight/obesity hereafter), grew for all 42 countries at about 0.7 percentage points per year on average. Using population weights, it is estimated that $19 \%$ of rural women and $37.2 \%$ of urban women are overweight or obese.

\section{Urban versus rural differences and the shifting burden of obesity toward the poor}

Figure 1 and Figure S1 in the supporting information online summarize the weighted absolute annual change and relative annual change in the prevalence of overweight/obesity and obesity only, respectively, among rural versus urban women by region. On average, urban women have higher baseline prevalence and larger increases in prevalence of overweight/obesity compared to rural women in the 42 countries surveyed ( 0.8 versus 0.5 percentage points for overweight; 0.4 versus 0.2 percentage points for obesity). However, there are regional differences, with rural women in Latin America, the Middle East, and North Africa having much higher increases in prevalence compared to their urban counterparts. The relative annual change in weighted prevalence is higher for rural (3.9\%) than urban (2.5\%) women. In other words, women in rural areas are quickly catching up to their urban counterparts. Figure S1 (available in the supporting information online) shows the statistics for obesity prevalence, and the results are consistent. The higher relative annual rates of change for obesity compared to overweight suggest that obesity prevalence, in particular, is changing very quickly.

We also looked at the data for each of the 42 countries in our study ranked by GDP per capita (see Figure S2 in the supporting information online). There appears to be little association between residence type and prevalence of overweight or obesity in countries with higher GDP. Among lower-GDP countries, urban women are

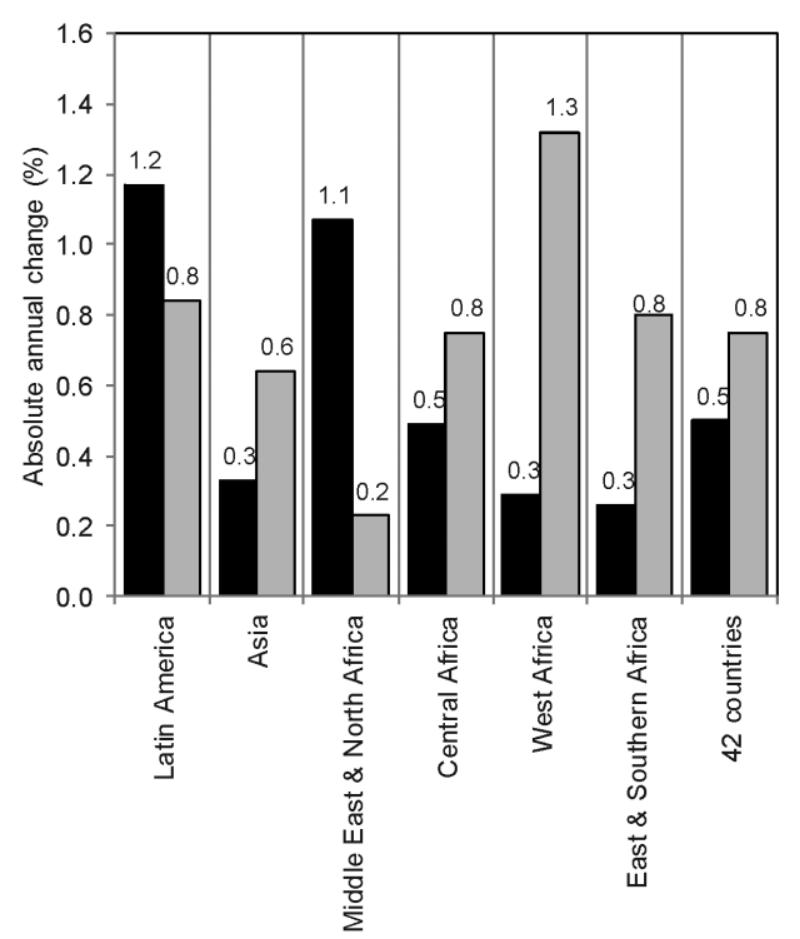

Relative annual change in OWOB (\%)

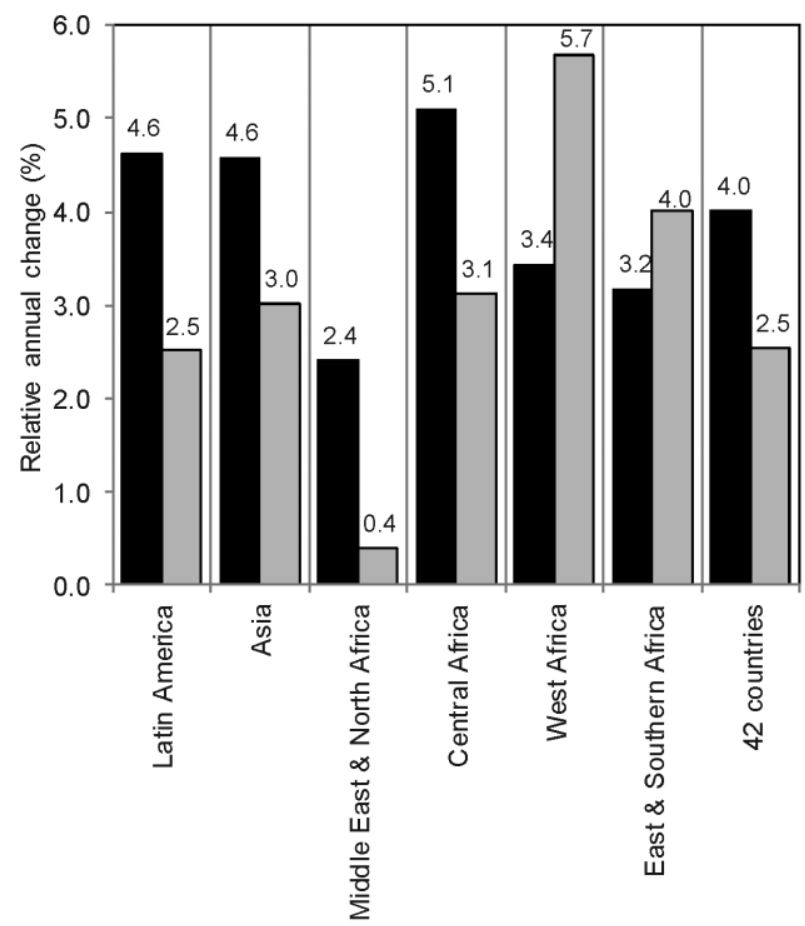

Figure 1 Absolute and relative annual percentage-point changes in weighted prevalence of overweight and obesity $(B M I \geq 25)$ among women in rural and urban areas of 42 countries by region $(\mathrm{N}=42)$. 
more likely to be overweight or obese, and countries around the middle and the bottom of the GDP distribution range have a higher proportion of urban women who are overweight or obese compared to rural women. Statistical analyses show that increased per-capita GDP is associated with increases in the absolute annual change in prevalence of overweight and obesity only in rural areas.

\section{KEY FACTORS EXPLAINING INCREASED OBESITY: POTENTIAL ROLE IN FUTURE PROGRAMMATIC AND POLICY MEASURES}

Ultimately, obesity reflects energy imbalance, so the major areas for intervention relate to dietary intake and energy expenditure, for which the main modifiable component is physical activity. It is clear that large shifts in access to technology have reduced work-related energy expenditure in the more labor-intensive occupations, such as farming and mining, as well as in the less energyintensive sectors such as service and manufacturing. ${ }^{23}$ Changes in transportation, ${ }^{24}$ leisure, and home production (cooking, cleaning, child care, etc.) ${ }^{25}$ have also led to reduced physical activity. In addition, the complex interplay between biological factors operating during fetal and infant development and the related energy imbalances exacerbate many health problems. ${ }^{26}$ Such changes have been well documented for China and are also found in varying manifestations in many countries.

Finding ways to increase physical activity across all age groups is important for public health, but options for increasing energy expenditure through physical activity may be limited in low- and middle-income countries. For instance, to offset any increase of about $110 \mathrm{kcal}$ of food or beverage in average daily energy intake, a woman weighing $54 \mathrm{~kg}$ must walk moderately fast for $30 \mathrm{~min}$ and a man weighing $82 \mathrm{~kg}$ for about $25 \mathrm{~min}$. Such levels of physical activity may be too much to expect, so dietary modification is a key approach to lowering obesity prevalence, particularly with the ongoing decline in physical activity and increase in sedentary time (unpublished data). The dietary dynamics represent a major set of complex issues. On the global level, new access to technologies (e.g., cheap edible oils, foods with excessive "empty calories," modern supermarkets, and food distribution and marketing) and regulatory environments (e.g., the World Trade Organization and freer flow of goods, services, and technologies) are changing diets in low- and middle-income countries. Accompanying this are all the critical issues of food security and global access to food sufficient to meet adequate levels of nutrient intake. Many populations focus on basic grain and legume food supplies, while the overall transition has shifted the structure of prices and food availability and created a nutrition transition linked with obesity as well as hunger. We have used detailed data on time use along with data on energy expenditures and other factors to examine past patterns and trends in order to predict, until 2020 and 2030, patterns of physical activity and sedentary behavior in the United States, the United Kingdom, Brazil, China, and India. ${ }^{27}$

Prior to exploring the dietary dimension, we consider an important biological factor affecting obesity and chronic diseases in rapidly developing countries in Asia and Africa. This factor is the biological insults suffered during fetal and infant development that may influence susceptibility to the changes described above, thus influencing trends in the development and severity of chronic disease in these countries.

\section{Developmental origins of health and disease: Special concerns for low- and middle-income countries}

The patterns of change in dietary intake and energy expenditure related to the global nutrition transition are particularly important in the context of current theories of the developmental origins of adult disease. Based on three decades of research, it is now recognized that susceptibility to obesity and chronic diseases is influenced by environmental exposures from the time of conception to adulthood. An extensive body of literature demonstrates that fetal nutritional insufficiency triggers a set of anatomical, hormonal, and physiological changes that enhance survival in a "resource-poor" environment. ${ }^{28}$ However, in a postnatal environment with plentiful resources, these developmental adaptations may contribute to the development of disease. Some of the strongest evidence on the long-term effects of moderate to severe nutrition restriction during pregnancy comes from follow-up of infants born after maternal exposure to famine conditions, such as those experienced in parts of Europe during World War II. For example, AC Ravelli et al. ${ }^{29}$ found higher rates of obesity in 50 -year-old men and women whose mothers were exposed to the Dutch famine in the first half of their pregnancies, and GP Ravelli et al. $^{30}$ found obesity among 19-year-old men whose mothers experienced famine during their pregnancies. Similarly, a follow-up of Hmong refugee immigrants revealed higher rates of central obesity among those raised in a war zone, with the effects amplified in those who migrated to the United States compared to those living in a traditional rural setting. ${ }^{31}$

The developmental origins theory of mismatch fits closely with the broader issues of mismatch discussed below, which emerged in our early research ${ }^{1,2}$ and later work. $^{32-34}$ The mismatch theory of early nutritional deficits followed by later excesses ${ }^{35}$ may be particularly important in low- and middle-income countries undergoing rapid social and economic changes, because 
economic progress amplifies mismatch. Much of the literature on the developmental origins of health and disease focuses on chronic diseases. However, given the strong association between chronic diseases and obesity, particularly central obesity, this evidence is highly relevant and provides a strong rationale for obesity prevention efforts in populations that have experienced dramatic changes in the nutritional environment as a consequence of nutrition transition.

Mechanisms may include effects on the number of nephrons in the kidney, ${ }^{36}$ glucocorticoid exposure subsequent to maternal stress, or poor nutritional status potentially programming the insulin and hypothalamicpituitary axes for high levels of metabolic efficiency ${ }^{28}$ and epigenetic changes. Maternal stress and specific aspects of diet (for example, intake of folate and other methyl donors) can affect DNA methylation and gene expression. ${ }^{37-39}$ Ongoing studies in places such as India are examining the role of maternal micronutrient intake on epigenetic changes that affect child adiposity. ${ }^{39,40}$ Research in India has provided other important insights. For example, Indian infants with poorly nourished mothers are born with weight deficits, but in relative terms the deficits in lean mass are greater than those in adiposity. In later life, when modern high-energy and high-fat diets are consumed, the previously "thin-fat" babies also have greater central adiposity. ${ }^{41,42}$

It is apparent from studies of the developmental origins of disease that there is a strong intergenerational component to health. While much of the literature on the early origins of obesity and associated risk has focused on undernutrition, there is also substantial evidence that maternal overweight and obesity in pregnancy influence disease risk among offspring. For example, gestational diabetes is related to offspring body composition and increased risk of insulin resistance and diabetes in offspring. ${ }^{43,44}$ Thus, there is concern about an intergenerational amplification of diabetes risk. Women who were malnourished as children are at increased risk of being centrally obese and having impaired glucose tolerance as adults. If these conditions affect a woman's pregnancy, her offspring will be at increased risk of early development of obesity and diabetes. As obesity develops at younger and younger ages, the likelihood that adolescents and young women who become pregnant will experience complications associated with gestational diabetes and hypertension will increase dramatically. There is growing evidence that maternal obesity, even without gestational diabetes, is a risk factor for child obesity through a pathway related to fetal overnutrition (see the review by Fall ${ }^{45}$ ).

On the other end of the nutrition spectrum, short maternal stature acts as a physical constraint on fetal growth, ${ }^{46,47}$ and stunting in offspring may, in turn, relate to increased obesity risk. ${ }^{48}$
Beyond the fetal period, nutrition and other contributors to health in infancy, childhood, and adolescence are important determinants of adult body composition and obesity risk. In light of the large increases in overweight and obesity in children as well as adults, attempts have been made to determine the ages at which faster weight gain relates to later obesity. A large body of literature relates "rapid growth" during infancy to risk of obesity in later childhood and into adulthood. ${ }^{49}$ In addition, rapid weight gain, particularly from mid-childhood onwards, is related to increased risk of elevated blood pressure or impaired fasting glucose in young adulthood in low- and middle-income countries. ${ }^{50}$ Concerns have been raised about the promotion of rapid weight gain in children who are malnourished. In low-income countries catch-up or compensatory growth following a period of faltering growth is desirable, because it is associated with reduced morbidity and improved survival ${ }^{51-53}$ as well as better cognitive development. ${ }^{54} \mathrm{~A}$ key concern, however, is whether the benefits of faster growth in these settings outweigh the possible long-term risks. Based on the COHORTS analysis of children from five low- and middle-income countries, faster weight gain in the first 2 years of life has a number of benefits. It is associated with the development of lean body mass but not with increased risk of impaired fasting glucose or diabetes in young adulthood (data submitted for publication: e.g., Kuzawa et al..$^{55}$ ). In light of observations that patterns of child growth have important consequences for the development of obesity and chronic diseases, another line of research focuses on factors that contribute to or protect against early development of adiposity. In this regard, the potential programming roles of early diet have been explored, including the roles of breastfeeding and high intakes of dietary protein, fat, and sodium. These topics are important in light of the dramatic changes in diet composition that characterize many populations in the developing world.

Of course, early feeding issues are important. Some studies show a protective effect of breastfeeding on later development of obesity and chronic diseases ${ }^{56,57}$ while other studies show no effects. ${ }^{58}$ Similarly, consistently high protein intake during complementary feeding in the first 2 years of life has been associated with a higher mean BMI and body fat percentage at 7 years of age in cohort studies of German children, ${ }^{59}$ and other researchers have suggested a strong link between high protein intake and obesity. ${ }^{60}$

Dietary fat (both the amount and the composition) may also play a role in the development of noncommunicable diseases. The STRIP study in Finland demonstrated that lower total and saturated dietary fat intake in infancy results in lower serum cholesterol, LDL cholesterol, and triglyeride levels (as well as lower blood pressure) in children up to 14 years of age, 
even without effects on height, weight, or BMI. ${ }^{61,62}$ Worldwide, the increase in plant-oil consumption has increased the intake of $n-6$ fatty acids and the ratio of n-6 to n-3 fatty acids. This is a concern, because high intake of n-6 fatty acids is associated with altered immune function, differentiation of preadipocytes into mature fat cells, and changes in fat deposition patterns. Another study relates high sodium intake from infant formula and weaning foods to increased blood pressure in adulthood. ${ }^{63}$

\section{Dietary changes}

The knowledge emerging from developmental origins research addresses only one dimension of the shift toward greater obesity. While early life exposures and biological insults appear to enhance the adverse effects of dietary change, in the end, shifts in energy balance and the entire structure of the diet have played major concomitant and separate roles. Here, we will speak first of broad trends and then return to the issues of poverty and availability. These link the set of dynamic changes in our food supply with food security.

It is useful to understand how vastly diets have changed in low- and medium-income countries to converge on what is often termed the "Western diet." This is broadly defined by high intakes of refined carbohydrates, added sugars, fats, and animal-source foods. Data available for low- and middle-income countries document this trend in all urban areas and, increasingly, in rural areas. Diets rich in legumes, other vegetables, and coarse grains are disappearing in all regions and countries, and some major global developments in technology are associated with this shift.

Edible oil and vegetable oil revolution. Fats have major benefits in terms of improving the flavor of food. Some scientists suggest that the selection of fat-rich, as opposed to carbohydrate-rich, foods is primarily determined by brain mechanisms that may include central levels of neurotransmitters, hormones, or neuropeptides. ${ }^{1}$ In the 1950s and 1960s in the United States and Japan, technology was developed to cheaply remove oils from oilseeds (e.g., corn, soybean, cottonseed, and red palm seeds). ${ }^{1}$ Breeding techniques to increase the oil content of these seeds accompanied the processing shifts, and higherincome countries saw a large increase in the availability of cheap vegetable oils. This was followed by the removal of erucic acid from rapeseed oil to create healthier canola oil, which was accompanied by extensive research on the good and bad components of each edible oil (e.g., trans fats and specific fatty acids). By 2010, inexpensive oils were available throughout the developing world. Between 1985 and 2010, individual intakes of vegetable oils increased between three- and sixfold in the developing world, depending on the subpopulation studied. In China, which has moderate, but not high, vegetable oil intake, persons aged 2 years and older consumed, on average, almost 300 calories and more than 30 grams of vegetable oil daily in $2006 .{ }^{64}$

Caloric sweeteners. Diets around the world are much sweeter today than heretofore. ${ }^{65}$ For example, $75 \%$ of foods and beverages bought in the United States contain added caloric sweeteners and the average American aged 2 years and older consumes about $375 \mathrm{kcal} / \mathrm{day}{ }^{66,67}$ In the United States, one of the few countries in which the amount of added sugar in the diet is estimated, ${ }^{68}$ research has shown remarkable stability in the amount of added sugar intake from food over the last 30 years, while the amount of added sugar from beverages has increased significantly. ${ }^{66}$ In 1977-78, two-thirds of added sugar in the US diet came from food; today, two-thirds comes from beverages. ${ }^{66}$ However, this may be an underestimate, since the added-sugar estimates from the US Department of Agriculture exclude fruit juice concentrate, which is a source of sugar that has seen major increases in consumption in the last decade and is now found in over $10 \%$ of US foods (unpublished data). Mexico, which experienced a doubling of caloric beverage intake to more than $21 \%$ of the kilocalories/day for all age groups from 1996 to 2002 is one of the few developing countries with data on caloric beverage patterns and trends. ${ }^{32,69,70}$ While individual dietary intake data are not available for most low-income countries, national aggregate data on sugar available for consumption (food disappearance or food balance data) suggest this is a major concern in all regions of the world. ${ }^{65}$

Shift toward increased animal-source food intake. Earlier research by Delgado ${ }^{71}$ and others at the International Food Policy Research Institute found the beginning of a livestock revolution in the developing world. Subsequent research has shown major increases in the production of beef, pork, dairy products, eggs, and poultry across lowand middle-income countries. ${ }^{72,73}$ Most of the global increases in animal-source foods have been in low- and middle-income countries. For example, India has experienced a major increase in consumption of dairy products and China in pork and eggs.

Increased consumption of animal-source food products has both positive and adverse health effects. On the one hand, for poor individuals throughout the developing world, a few extra grams of animal-source foods can significantly improve the micronutrient profile of the diet. On the other hand, excessive consumption of animal-source foods is linked with excessive saturated fat intake and increased mortality. ${ }^{74,75}$ 
Reduced intake of legumes, coarse grains, and other vegetables. While significant systematic research on the reduced consumption of these nutritionally important foods has not been undertaken, it is clear from case studies that consumption of beans, a vast array of bean products, and what are often termed "coarse" grains, such as sorghum and millet, has declined significantly. ${ }^{6,76,77}$ This occurred from the 1960s through the 1980s in the United States and, more recently, across Asia and the rest of the Americas. ${ }^{78}$

Understanding the reasons underlying the trend toward increased consumption of animal-source food, oils, and caloric sweeteners and the reduced consumption of legumes, coarse grains, and other vegetables begins with understanding the relative shifts in price structure that have occurred since World War II. Most of these changes are purposeful and relate to agricultural policies around the world. ${ }^{6,79}$

\section{Food system changes}

In the past $10-15$ years, several factors have influenced the food supplies of individual countries. The food system characterizing most urban, and an increasing proportion of rural, areas across low- and middle-income countries has changed drastically with 1) the globalized distribution of technology related to food production, transportation, and marketing, 2) mass media, and 3) the flow of capital and services. Access to many new foods and beverages with empty calories relates to current economic and social development. Modern food technology has provided enormous and myriad benefits including reducing food waste, enhancing sanitation, and reducing many adverse effects of seasonality. The same is true for the modern supermarket. While the critical benefits of these important changes to producers and consumers are acknowledged, highlighted here are some of the potential adverse effects.

A key component of food system changes is modern food distribution and sales. This is reflected in the enormous penetration of super- and megamarket companies throughout the developing world.$^{80}$ Most countries also have large convenience store chains. The fresh market (wet or open public market) is disappearing as the major source of food in the developing world and is being replaced by large regional and local supermarkets, which are usually part of multinational chains (e.g., Carrefour or Walmart) or, in countries such as South Africa and China, by domestic chains that function and look like the global chains. Increasingly, hypermarkets (megastores) are the major force driving changes in food expenditures in any country or region. In Latin America, for example, supermarkets' share of all retail food sales increased from 15\% in 1990 to $60 \%$ by 2000 . In comparison, supermarkets in the United States accounted for $80 \%$ of retail food sales in 2000. This process is also occurring at varying rates in Asia, Eastern Europe, the Middle East, and all urban areas of Africa. We will undertake a national survey of diet and related factors in India in 2012.

One report of a study performed in Guatemala suggests that shifts in the food environment might enhance intake of processed, lower-quality foods.$^{81}$ Carlos Monteiro has been particularly clear in expressing his concern that the modern food environment has impacted diets. ${ }^{4,5}, 82$ Indeed, his concern regarding food processing meshes well with the vast shift away from consumption of legumes and coarse grains to consumption of refined grains purchased at modern supermarkets and convenience stores, which have penetrated urban Africa and Asia and most of the Middle East and Latin America.

The potential adverse effects of these trends are associated with increased access in developing countries to cheaper, processed foods that are high in fat, added sugar, and salt. At the same time, the trends provide some benefits. For example, supermarkets were instrumental in the development of ultra-heat treatment for the pasteurization of milk, giving it a long shelf life (not requiring refrigeration) and providing a safe source of milk for all income groups. Supermarkets were also key players in establishing food safety standards. ${ }^{83}$ Most importantly, they solved the cold chain problem and, in many instances, brought higher-quality produce to the urban consumer throughout the year. Other factors include the liberalization of direct foreign investment, trade liberalization, and the saturation of Western markets that has pushed growing companies into other locales. Improvements in the logistics and procurement systems used by supermarkets have allowed them to compete, on cost, with the more typical outlets in developing countries - the small momand-pop stores and wet markets (fresh or open public markets) for fruits, vegetables, and all other products.

Another result of the global changes in food consumption is the freer flow of food trade linked with the World Trade Organization. For instance, barriers to imports of edible oil have been reduced, and vegetable oil production has been centralized to compete with imports and to significantly lower the prices of vegetable oil in countries such as China.

These changes, along with global investments in agriculture over the last half century, have produced a large shift in relative prices to favor animal-source foods, edible oils, and other key global commodities, including sugar. ${ }^{79}$ In the supporting information for this article available online, Figure S3, reproduced from research at the International Food Policy Research Institute, highlights some of the global trends that have resulted from the vast investment in the animal foods sector and feed crops across the globe. ${ }^{71,79}$ Also in the supporting information, Figure S4 highlights the real shifts in China in terms of 
the relative costs of selected foods, based on data from 330 communities and their food markets. ${ }^{84}$

\section{Food security and the dual burden of undernutrition and obesity}

This rapid transition in income and diet and the large shift toward animal-source food consumption creates major demands for basic grains to feed livestock, disregarding the needs of the poor for the same food supply. While drought, climate change, and increased demand for ethanol have contributed to global food prices, the longer-term structural shift relates to demand for animalsource food and its impact on corn, rice, and wheat prices. Alongside the real need for basic foods for the poor, the marketing, desirability, and availability of such items as low-cost edible oils and empty-calorie foods have encouraged the urban poor to consume lower-quality foods that are obesogenic; these are widely believed to most likely be the more heavily processed foods, but this has not yet been documented. These complex changes are reflected in the emergence of obesity alongside hunger, even in the same households.

Families faced with an inability to grow food or inadequate income to purchase food will likely opt for the cheapest cost per calorie from the available choices. When food prices for basic grains double or triple, the pressures to adjust food purchases increase. Among the most salient issues are the vulnerability of poor, female-headed households $s^{85}$ and the combination of price increases and volatility in global food markets (linked also with climate change issues). It is also important to note that the relative price changes matter most. If the prices of fatty foods, oils, sugar, and animal-source foods go down relative to legumes, fruits, and other vegetables, the latter items become less attractive.

Despite substantial economic growth, large inequalities remain in many low- and middle-income countries, and it is common to see problems of underweight, stunting, and micronutrient deficiencies side by side with increasing rates of obesity. This dual burden of undernutrition and obesity exists not only within countries and communities, ${ }^{86}$ but also within households ${ }^{87,88}$ and even in some individuals, who may have excess adiposity along with micronutrient deficiencies, such as iron deficiency anemia, ${ }^{87-90}$ or stunting and overweight. Dual-burden households are most common in countries undergoing nutrition transition, ${ }^{87,88}$ and the circumstance may be a reflection of differences in food allocation related to social norms based on gender or generation. For example, high-quality foods may be given preferentially to adult males rather than to children. But other patterns may exist as well. In China, for example, it is common for parents to indulge their children in the wake of the coun- try's one-child strategy for population control. ${ }^{91,92}$ Individuals of different generations may also respond differently to social and economic changes, with the younger generation adopting new dietary patterns more quickly, while the elderly continue to eat in more traditional (and sometimes healthier) ways.

A challenge for food programs and policies is the need to address food insecurity and hunger without adding to the burden of overweight and obesity. This is particularly challenging given the relatively low cost and high availability of foods that are energy-dense but low in micronutrient content. Again, it is relative prices that matter. The lack of focus on coarse grains, legumes, and other vegetables and the vast attention to sugar crops, oilseeds, vegetable oil technologies, and cheaper animalsource foods have contributed to the global shift in diets.

In countries such as Mexico, Brazil, Chile, and China, where great strides have been made to minimize acute malnutrition through programs targeting vulnerable subpopulations, hunger and malnutrition have been reduced. One example is Oportunidades, the conditional cash transfer program in Mexico that provides a stipend and complementary food for preschoolers. ${ }^{93,94}$ It is recognized that such programs must be tailored to address malnutrition while not accelerating energy imbalance and obesity among the recipients, as has occurred in some programs. ${ }^{93,95}$ For instance, Chile continued to feed young children in its various feeding programs even when most were adequately nourished; the programs were not revised to deal with energy imbalance issues for some time after undernutrition was successfully reduced..$^{95}$ To address child obesity in Mexico, the Mexican government found it necessary to reduce the fat content of the milk distributed in its feeding programs, along with other changes.

\section{CURRENT EXPERIENCES AND MAJOR INITIATIVES}

One of the major gaps in the area of large-scale, healthrelated interventions that needs to be filled is rigorous evaluation of existing programs and initiatives followed by refinements to enhance their efficacy. In fact, with one exception, across the globe there have been no rigorous evaluations or reviews of interventions in terms of their impact on diet or obesity. The one exception is Mexico, where the effects of welfare and feeding programs on obesity were evaluated. ${ }^{93,95}$ The evaluation was designed as part of a large quasi-experimental study of welfare in Mexico and was not designed to examine the food component. Thus, it is impossible to highlight in any unbiased manner what might and might not work. In essence, no funding has existed for evaluation activities across the low- and middle-income world.

The lack of appropriate technology and environments to foster beneficial change is a critical health issue. 
In many ways, it would be ideal to refocus attention on these points and away from what is often perceived as irrational behavior and ignorance governing individual and household consumption patterns. Across the globe, the major focus is on education. This focus is identical to the way agriculture systems assisted farmers across the globe. Ignoring environmental determinants, outsiders assumed the poor were ignorant, lazy, illiterate peasants who would never change without technology, and the programs suffered from problems associated with the approach. With an understanding of appropriate versus inappropriate technologies and the rationale behind the decisions made by farmers and others, the development approach to agriculture changed completely ${ }^{96}$ and an appreciation of the interplay of literacy and education with technology and extension developed. ${ }^{97}$ However, in the health sector and in public health education there remains a perception that set goals will be met by providing the buildings and the technologies.

\section{Institutional and large-scale feeding programs}

As described earlier in this article, most of the large-scale initiatives to systematically address obesity, such as those in Brazil, Mexico, and Chile, have focused on schools. ${ }^{98}$ Brazil, for example, requires that a significant portion of expenditures come from local food. Some large-scale feeding systems have focused on low-income areas such as those providing low-cost food via community kitchens in Peru. ${ }^{99}$ Surprisingly, few examples of large-scale feeding have focused on providing a healthful diet that addresses concerns of obesity that exist in low- and middle-income countries.

\section{Education: Labeling and front-of-package initiatives}

Front-of-package labeling provides information that helps consumers make healthier food choices and stimulates product reformulation. This began globally with a desire to reduce saturated and trans fats, added salt, and added sugar in so-called empty-calorie foods and to enhance fruit, vegetable, and whole-grain intake while limiting energy intake. The most common approach is that promoted by an international program led by scientists at the Choices International Foundation. This product-specific nutrient-profiling approach has developed food categories, revised them to meet unique country- and region-specific dietary needs, and created food group-specific nutrition criteria to show what items represent a healthy choice. ${ }^{100}$ Recently, the US Institute of Medicine recommended a single front-of-package design somewhat similar to the Choices' approach, but the deliberations are still in process. ${ }^{101,102}$
Underlying this system is the need to reformulate a vast array of products to enhance their healthfulness. For instance, there are at least 200,000 packaged foods and beverages in the United States with unique formulations. ${ }^{67}$ Reducing their energy content and enhancing their quality is linked with this front-of-package labeling effort.

\section{Regulations regarding beverages and food marketing}

The World Health Organization (WHO) and other organizations have called for regulations to minimize or eliminate the marketing of less healthy foods and to consider ways to control consumption of sugary beverages.

Brazil and Chile have initiated controls over the marketing of unhealthful foods with an official national code of marketing. A second initiative relates to the control of sugar-sweetened beverages. A large number of global health groups (such as those concerned with diabetes, heart disease, and cancer) have called for reductions in sugar-sweetened beverage intake. In some cases, this has included 100\% fruit juice, and in all cases it has included carbonated sugar-sweetened beverages, fruit drinks, energy drinks, sports drinks, and vitamin waters. More than 20 countries have prohibited vending machines in schools and prohibited sales of these less healthful foods by outside vendors on school grounds.

Mexico is one of the few low- or middle-income countries to aggressively move against sugar-sweetened beverages and other high-calorie, less healthful beverages (e.g., full-fat whole milk versus $1 \%$ reduced-fat milk). In Mexico, the Ministry of Health created a set of beverage guidelines that the government used to change procedures in their feeding and welfare programs and in schools. ${ }^{32}$ An as yet unaddressed area is foods high in saturated fats and added sugars. Called "junk foods" or foods with excessive amounts of "empty calories," these represent an increasing portion of diets across the globe. ${ }^{4,5,82,103}$ There is very limited research to show what increasing the costs of such foods might do to diets overall. ${ }^{104}$ Would people just substitute other refined carbohydrates or fried foods? Would calories be cut? Could this lead to healthier food choices? There is a great need for well-monitored and -evaluated small- and large-scale studies of such activities prior to promoting them, and there is a need for research using extant data to understand how price shifts might affect the structure of diets.

\section{Schools}

As noted above, countries throughout the world have focused on school feeding and vending policies. Examples as simple as providing potable water along with water education show that even small efforts with an initial 
investment and small marginal costs can have an impact. $^{105}$

\section{Country-specific initiatives}

While there are unique issues in many countries, Mexico is focused on here due to space constraints. Mexico experienced one of the world's largest increases in obesity, diabetes, and cardiometabolic diseases in the 1990-2010 period. ${ }^{106-108}$ It is one of the very few countries aggressively pursuing a full-scale effort to slow down and reverse the obesity trend. First, the government addressed calories consumed from beverages, including excessive calories from whole milk, sugar-sweetened beverages, and heavily sweetened agua frescas (fruit juice, water, and added sugar). ${ }^{32}$ Among the major actions recommended by the government's Beverage Guidance Panel was the removal of all whole milk from government programs and replacement with $1.5 \%$ milk. This was followed in 2010 by development of an Obesity Prevention Strategy signed by all ministers and the president. More recently, an agreement between the major Mexican food companies and the Ministries of Health and Education removed most foods and beverages with high sugar and high saturated fat content from schools. The government also established a front-of-package initiative to provide Ministry of Health-approved healthy food labels for foods with reduced sodium, sugar, and saturated fats along with more healthful components.

In comparison, Asian countries have generally done little, but Singapore and Thailand are exceptions. In Thailand, efforts have been led by key nutritionists and Princess Maha Chakri Sirindhorn. The government has started a number of infant feeding and school initiatives related to obesity prevention. They have revised food labeling, increased promotion of fruits and vegetables, and worked on reducing the fat and oil content of foods, but they have not yet invested significant resources or developed a comprehensive program.

In Latin America, Brazil and Chile are initiating a number of measures; however, the efforts have and will continue to come up against food industry concerns, as highly processed and unhealthful foods are found in schools and elsewhere. ${ }^{109}$

\section{FUTURE OPTIONS AT THE COMMUNITY AND LARGE-SCALE LEVELS}

If we are to prevent obesity and reduce the rapid increases in global obesity, the prime focus must be on the food supply and improving the quality of diets while reducing total caloric intake. From the intervention, programmatic, and policy perspectives, this is the area with most potential. Will interventions in pregnancy and infancy represent the key to preventing future overweight? Can such interventions work without major shifts in energy imbalance and thus in diets in later life?

A second and equally important set of questions relates to improving diets at all ages. Can we recover all the healthful elements of diets lost over the last half century (e.g., beans or legumes from many countries, coarse grains and whole-grain products from others, vegetables from many)? How do we reduce the excessive consumption of sugar-sweetened beverages, fatty, salty and sugary refined carbohydrate foods termed ultraprocessed foods by Monteiro, junk foods by some, and empty-calorie foods by others. ${ }^{4,5,68,110,111}$ Are measurement methods in the current food systems adequate to address our concerns about diet quality and quantity ${ }^{67}$ ? While changes in food systems are linked with dietary shifts, the changes in the overall global food systems are so profound for low- and middle-income countries that they are discussed briefly as a third concern. A fourth area relates to the health sector and its role in addressing these food and nutrition issues. Is its role to advocate and work for regulations or to work with others to educate the public? Fifth, we find food insecurity, major constraints on the poor, and many of the issues of poverty and low education affecting obesity just as they affect differentially the problems of hunger and malnutrition. What can the food insecurity literature suggest about addressing obesity in the developing world?

\section{Direct feeding, care, and prevention interventions at the community level}

What options emerge from the developmental origins theory? Consideration of the developmental origins of obesity and chronic diseases is important because 1) there is strong evidence to support a role for early-life exposures in the development of later disease risk, 2) there is potential for intergenerational amplification of risk, and 3) prevention efforts can capitalize on the same developmental plasticity that alters susceptibility to disease to intervene early to prevent obesity. As stated by Peter Gluckman, the "greatest leverage in terms of reduction of risk can be achieved through a timely intervention in the developmentally plastic phase." ${ }^{35}$

The first 1,000 days. Current focus for child survival and healthy growth and development in resource-poor settings is on the first 1,000 days. ${ }^{112}$ This begins with pregnancy, with attention needed to ensure high dietary quality, including micronutrient adequacy, and to optimize pregnancy weight gain, avoiding inadequate as well as excessive gains. ${ }^{113}$ However, since early pregnancy matters, it is vital that interventions optimize the health and nutritional status of young women prior to preg- 
nancy. This implies a need to focus on the period from childhood to adolescence as well in order to promote linear growth, minimize excess gains in adiposity, and establish healthy patterns of diet and physical activity. Recent attention has focused on young girls as an important target for improving health (e.g., Center for Global Development, Bill and Melinda Gates Foundation, Start with a Girl: A New Agenda for Global Health [http:// www.cgdev.org/content/publications/detail/1422899/], and Girls Count: A Global Investment and Action Agenda [http://www.cgdev.org/content/publications/detail/ 15154]). This focus is also important in light of the fact that in several low- and middle-income countries, such as South Africa and Guatemala, obesity increases sharply in girls in the years following menarche ${ }^{114}$ putting young women at risk for pregnancies complicated by obesity as well as micronutrient deficiencies.

Some adverse effects related to feeding deserve careful consideration in program and policy work. Limited evidence from randomized clinical trials in highincome settings shows that a higher protein content in infant formula is associated with higher weight in the first 2 years of life but has no effect on linear growth ${ }^{115}$ and that feeding a nutrient-enriched formula to infants who are small for their gestational age is related to higher fat mass in mid-childhood. ${ }^{116}$ In Finland, a randomized study of individualized dietary and lifestyle counseling to reduce intake of saturated fat decreased the prevalence of overweight in school-age girls. ${ }^{117}$ These studies demonstrate the potential for dietary modification to influence obesity risk. Experimental evidence from low- and middle-income settings on dietary interventions to reduce obesity in infancy and childhood is lacking. Most nutrition intervention trials have been geared toward the amelioration of stunting and enhancement of growth of malnourished children.

Research is needed to define an optimal weaning and early childhood diet that promotes linear growth and lean body mass while minimizing excess adiposity. An extensive body of literature has explored whether breastfeeding reduces the risk of child obesity and it generally finds only small or minimal protective effects. However, breastfeeding is well known to contribute to healthy growth and to reduce stunting, which is, in turn, associated with later overweight in low-income populations. ${ }^{118}$ Thus, the promotion of breastfeeding has value in the context of obesity prevention in low- and middle-income countries.

While there is an appreciation of the potential importance of intervening in pregnancy and infancy to prevent later obesity, ${ }^{119}$ there is a lack of specificity about the components of potentially successful interventions. This reflects a lack of knowledge relevant to early obesity prevention in low- and middle-income countries. Moreover, investigators are just now beginning to assess the relative importance and potential impact of prenatal versus postnatal effects and the relative importance of different periods (infancy, childhood, adolescence). Owing to the relatively recent acceptance of the premises put forth to support the developmental origins of adult disease risk and the need for long-term cohort studies to test interventions, there is, as yet, no empirical evidence to support such efforts as a means to influence obesity and chronic disease risk. However, several trials have been initiated, but have yet to be published. For example, in Pune, India, Yajnik and colleagues have begun to provide nutritional supplements to adolescent girls prior to and during pregnancy.

Clearly, there is a large and presently unmet need to explore the implications of interventions based on developmental origins concepts, but it is essential to include a life-course perspective that recognizes intergenerational risks and the importance of infant and young child nutrition. Given the persistent problems of poor nutrition (stunting, impaired intellectual development, increased morbidity) that coexist with the development of child obesity, it is critical that interventions be geared to optimize nutritional status through careful attention to diet quality and composition with the aim of enhancing linear growth, eliminating micronutrient deficiencies, and preventing obesity.

\section{Focus on the food supply}

The question that arises repeatedly is, why can't we just return to earlier, healthier components of traditional diets in Asia, Africa, and other transitional regions of the world? Here, a set of options is grouped in a manner consistent with that used by the International Obesity Task Force.

Food-related fiscal measures. Are there ways to shift diets towards (or back to) healthier components? Can we alter relative prices? Can we learn ways to promote legumes and other vegetables that link naturally with food system development? A major area of concern across the globe is the loss of overall healthy dietary patterns and the removal of key components of the diet. The thinking is that since dietary patterns shifted greatly in a span of 10 to 20 years, they can shift again just as readily.

The first problem relates to the relative prices of foods consumed as basic staples prior to the major dietary changes of the past 20-50 years. These include whole grains, legumes, other vegetables, and fruits that many scholars felt were part of the healthier components of diets across the globe before the 1960s. Relative prices globally have reduced the cost of animal-source foods, oils, sugar, and related products. ${ }^{79}$ Removal of subsidies in the United States and Europe might not appreciably alter 
the relatively lower prices of animal-source foods, oils, and sweeteners, among others. ${ }^{120,121}$ In contrast, there is no research on the role subsidies play in the shift in the overall structure of diets in low- and middle-income countries. Such work is needed to fully understand if government interventions, which are numerous in most Asian, African, and Latin American countries, adversely affect the quality of the diet and are linked with excessive caloric intake. In 1989, a conference was held in China that discussed the future problems with obesity, the large subsidies of fatty pork, and the reduced intake of legumes, especially soy and soy products, in China. The Chinese Ministry of Agriculture subsequently made a small effort to reduce the pork subsidy. (It should be noted that the conference was a joint endeavor of the Chinese Academy of Medical Sciences and Chinese Academy of Agricultural Sciences, and the Ministries of Health, Rural Development, and Agriculture were also involved). ${ }^{78,120,121}$ It is presently unclear if it is possible to adjust relative pricing and preferences in favor of more healthful foods, but this represents one key global long-term goal.

One of the major targets of efforts to rapidly improve public health has been the taxation of select foods and beverages, particularly sugar-sweetened beverages. Many countries have initiated discussions about implementing, or have attempted to add, sugar-sweetened beverage taxation, and some global organizations, such as the World Cancer Research Fund and the World Heart Federation, have made this a central cause in their work. Mexico provides a prime example of how a government initiative has been implemented to control sugar-sweetened beverage consumption in schools and thereby reduce the number of calories consumed from beverages. ${ }^{32,69,70}$ Worldwide, over 20 countries have banned all sugary beverages from schools, and about 12 have banned 100\% fruit juice as well. Limited literature supports the potential benefits of taxation of sugary beverages. ${ }^{7,12,122-125}$

Monteiro has raised the controversial question of whether it is possible to remove some of the heavy reliance on ultraprocessed food. He defines ultraprocessed foods as basically confections of processed foods, typically with the sophisticated use of additives to make them edible, palatable, and habit-forming. He feels this leaves the food products with no real resemblance to regular food (e.g., commodities such as produce or meat), even though they may be shaped, labeled, and marketed to seem wholesome and fresh. ${ }^{4,5,82}$ Monteiro claims that ultraprocessed foods are a problem because they readily induce overeating and are a major source of empty calories. In many ways, this argument echoes the desire of Michael Pollan and other authors around the globe who want to see a return to the consumption of basic commodities like fruits, vegetables, poultry, and other meat but no ultraprocessed foods (or very limited use of such foods). ${ }^{126}$
Given the dominance of a large and complex chain of food handling from farm to consumer, with varying degrees of processing affecting all foods, it is hard to know what to label as an ultraprocessed food. Further, the practicality of these initiatives from both a global hunger and an environmental perspective has yet to be examined. In the case of ultraprocessed food, the question of whether or not we can we actually provide healthier food for large populations across the globe remains. For elites, income, time, and price constraints may not be as restrictive as for other socioeconomic groups, and there are indications that shifts towards more natural foods may be occurring in this group. Evidence of this includes the rebirth of farmers markets (wet markets) across the United States and other high-income countries, growth of the Slow Food movement, and even the growing availability of organic food in the global food supply. However, globalization of the food supply, technological advances in processing and preservation, and the ultraprocessing of food may be so far along that it is impossible to return to simpler, more traditional ways of obtaining food and preparing it.

Private sector voluntary initiatives. Is it possible to work with global and national food companies to enhance the quality and reduce the caloric content of processed foods? Will voluntary initiatives work? Will food companies promote regulatory and other policy changes that address global obesity? And, can we succeed in improving diets if global companies (many of which are bigger than some nations in income and assets) do not cooperate? These are complex questions that are almost impossible to answer, and history has shown that cooperation is only possible in some cases. Many use the example of the battle against smoking behavior and tobacco use as the approach to be used in addressing the "bad" elements of the food supply. ${ }^{127,128}$ However, the scope and reach of the food companies is far greater than that of the tobacco companies, and the need for all consumers to eat food leads to complex issues when focus is sharpened on what many feel is an essential point - there are "good" foods to encourage and "bad" foods to discourage and it is no longer possible to rely on consumers to eat a "healthful" diet voluntarily.

Currently, several major global initiatives are underway. The one that seems most promising is the potential reduction of total calories proposed by 17 leading food companies. Their commitment in the United States is to remove 1.5 trillion calories from the total US supply of the processed foods they sell by 2015 . They have made no explicit agreements with other countries on the exact amount of calorie reduction; however, they are negotiating a similar arrangement in Australia. The US arrangement is under the umbrella of 
the Healthy Weight Commitment Foundation (http:// www.healthyweightcommit.org/). The University of North Carolina (UNC) Food Research Program team is the official outside evaluator of the effort. Even in the United States, these global giants control only about $25-30 \%$ of the total calories consumed. Therefore, there are questions not only about the true effectiveness of the changes in the companies' own sales models and products but also about consumer substitutions of other packaged and processed food and beverage products and other sources of calories.

Walmart is leading a second initiative in the United States in which it has pledged to cut the amount of calories sold, albeit without specifying a solid exact amount or a strong external evaluation plan. Furthermore, it is unclear how Walmart will translate this pledge to its global stores.

There is no clear evidence that these voluntary pledges will be linked with reduced energy intake, improve diet quality, or reduce obesity, even for the global companies. ${ }^{129,130}$ To date, studies on topics such as control of mass media marketing to children provide little evidence of any noticeable decline in marketing of empty calorie foods. ${ }^{131}$ Furthermore, these voluntary efforts seem to be focused on the United States, Europe, or other high-income countries and not the low- and middleincome world.

There is a key additional element. Global food companies are responsible for the major portion of sales of certain categories of foods, such as sugar-sweetened beverages, in low- and middle-income countries. However, there are numerous local food preparers, processors, and distributors. Even if global food companies reduce the caloric content of their products, it is unclear whether those products would simply be replaced by those of local competitors with higher caloric content. Our group is attempting to determine if we can even measure the reach of global food companies in countries as diverse as the United States and China. In higher-income countries, where governance is open, it is relatively simple to do; however, across the globe, the roles of global companies become much murkier and are often impossible to gauge accurately as information on ownership is not publicly obtainable. Further, there is the indirect impact of these companies on how foods are produced, processed, and distributed and even the types of products that companies want to market as food and drink. ${ }^{132} \mathrm{~A}$ publication by JL Watson showed how the introduction of McDonald's into Hong Kong, China, Taiwan, Japan, and other Asian countries affected the entire culture of food service and preparation in other restaurants. ${ }^{132}$

The United States and Western Europe have implemented food safety and labeling controls and careful monitoring of many components of marketed food, but what will happen as global food and agribusiness compa- nies become active in low- and middle-income transitional economies? As with tobacco, will "junk food" and unethical marketing be focused on low- and middleincome countries? Our team at the University of North Carolina has found some evidence of this in the sugarsweetened beverage arena. ${ }^{3}$ We conducted a case study of the two largest and most influential producers of sweetened beverages, the Coca-Cola Company and PepsiCo, who, together, control $34 \%$ of the global soft drink market and $69 \%$ of the carbonated soft drink market. We examined how they adjusted their product portfolios globally and in three critical markets (the United States, Brazil, and China) in 2000-2010. On a global basis, total revenues and calories sold per capita increased. In the United States, both total calories per capita and calories per ounce sold decreased, while the opposite was true in the developing markets of Brazil and China. Total calories per capita increased greatly in China and, to a lesser extent, in Brazil. ${ }^{3}$ It is quite possible that such shifts will cross into many other categories of food. It is clear that the declines in kcal/ounce in the United States reflects a shift toward greater marketing of low-calorie options. It might also reflect the increased demand for low-calorie beverages, but it is impossible to untangle supply and demand. In Brazil, despite the increased attention to obesity and large declines in obesity among women, there is no evidence of a shift in consumption patterns (unpublished data).

\section{Healthy public policies}

Where does the public health system fit into this? In many countries, the modern medical sector represents a major contact point for individuals during critical times in the life cycle (pregnancy, infancy, and aging). Also, modern medical practitioners are held in high esteem. The public health sector thus has a particularly important role to play through its contact with individuals and families in many countries. At the same time, when it comes to guidance related to obesity, there are few examples at the provincial/state or national levels in which this sector has been mobilized and used effectively to prevent obesity. Rarely is there evidence that nurses, physicians, and other medical professionals raise and discuss intelligently the issues of proper diet and physical activity patterns.

Negative effects of current programs focused traditionally on undernutrition. As the experiences in Mexico and Brazil show, traditional poverty alleviation and food programs can have unforeseen consequences, especially in environments in which activity patterns have become more sedentary. Are there current food and nutrition programs that actually increase the risk of obesity in Asia, the Middle East, and Africa? What about other macroeconomic policies? This, again, is an under-researched area. 
As noted in reports of studies performed in Chile and Mexico, there is the potential that current feeding programs can be focused on reducing hunger and malnutrition, but instead of requiring additional calories, their target populations may need higher-quality foods. The outcome may otherwise be increased weight gain and obesity. ${ }^{93,95,133}$ Little is known about this issue globally, since the focus has been primarily on the prevention or treatment of undernutrition, and data have not been systematically evaluated for potential effects on excess weight gain and obesity. As countries make the transition from reduced hunger and poverty toward less constrained food supplies, increased incomes, and modern infrastructure, there is a concomitant reduction in physical activity and in the quality of foods consumed - factors that are clear contributors to overweight and obesity.

Can schools promote change? Globally, there has been a large shift toward consumption of precooked and preprepared, highly processed, empty-calorie food. In many countries, knowledge about food and skills in food preparation and cooking are being lost as new generations grow increasingly reliant on food prepared in locations outside the home. ${ }^{6,134}$ To combat this problem, the United Kingdom built kitchens to teach cooking to boys and girls in middle schools throughout the entire country over the 2000-2010 period. ${ }^{135-138}$ Can school gardens and teaching exercises that enhance understanding of food and food preparation encourage the next generation to cook and consume healthier food? Little is known about this option.

A few studies suggest that such options might work, but rigorous evaluations do not yet exist. Nevertheless, in South Korea, a generation of young housewives was trained to cook traditional low-fat and healthy vegetable dishes. This was linked to high vegetable intake and low fat intake. ${ }^{139,140}$ Similarly, there is some evidence that training several generations of women in France to cook with portion controls might have been important for reduced portion sizes in France. ${ }^{6,141,142}$

Trade. Globalization and the World Trade Organization are often credited with opening the globe to free trade in food and services. ${ }^{143}$ There are effects such as reduced edible-oil prices and increased intake of these oils in China that can be linked to specific agreements, such as those addressing trade barriers to imports. However, modernization and increased trade go hand in hand with improvements in the quality of living that no country would willingly forego. The gap lies in our knowledge of specific components of trade agreements that might adversely affect diet and the effects of trade and economic policies on dietary patterns.
Marketing of unhealthy food to children. A prime area of concern is how food marketing to children contributes to an obesogenic environment. The role of media - televisions, computers, notebooks, or cell phones - has expanded in use and impact. The media have ready access to the consumer, and the global penetration is such that not a household, village, or urban sector is missed. At the same time, product placement in movies, on billboards, and elsewhere has created an environment in which children and adults are assaulted with visions of eating and drinking that are creating global shifts in food demand. Thus, a prime target for combating obesity is media control, though all initiatives to date have focused only on marketing to children and not on the total marketing environment, as occurred with early efforts to control tobacco advertising. ${ }^{127,128,144,145}$ Control of advertising represents a major aspect of tobacco control in countries that have seriously reduced tobacco use. There may, thus, be important lessons from the tobacco story that are relevant for food.

Public sector healthy food service policies. The public sector feeds enormous numbers of individuals in schools, hospitals, and government departments. Improving the quality of food served in these institutions remains another key measure. ${ }^{98}$ As with the marketing of foods, only minimal evaluations of initiatives in this sector as they relate to diet and body composition have been completed.

Food and nutrition labeling. Food labeling is emerging as a major global initiative. In Latin America, Asia, and Africa the focus is not only on providing "nutrition facts" panels on foods but also on developing systems for identifying which foods and beverages are deemed healthy according to the food customs of each country and global initiatives to reduce added sugar, trans fats, other saturated fats, and added sodium while encouraging consumption of whole grains, fruits, legumes, and other vegetables. ${ }^{100}$ India, China, Brazil, Mexico, South Africa, and Chile are all considering such initiatives. This is a very promising option as the global food supply increases in complexity, and consumers across the globe increasingly shift consumption to processed and packaged foods and to shopping in commercial chains, be they convenience stores, grocery stores, supermarkets, or megamarts.

\section{CONCLUSION}

In the past half century, there have been vast shifts in how humans eat and drink, the incidence of energy imbalance, overweight, and obesity, and the vast array of other 
nutrition-related cardiometabolic problems. Unfortunately, we do not have the data to document precisely how these changes compare with others over the course of human evolution. However, from our perspective, as individuals concerned with attaining a healthy diet and healthier body composition, it appears as if many adverse changes have accelerated in the past several decades across the globe. This does not mean that all of the changes that have occurred are perceived as harmful. In contrast, the improvements to food convenience and safety, the increasingly fatty, sweet, and salty diets, and the new and interesting beverages with great flavors bring many benefits. However, it is critical to evolve toward a healthier diet, and in many cases, a less processed diet with more nutrient-dense and healthier foods. To prevent future problems and to provide for those with nutritionrelated noncommunicable diseases, be they obesity, diabetes, a cancer, or others, it is imperative to improve dietary patterns around the world. Focusing on medical treatments, smoking reduction, and regulating sodium in the diet will not halt the rising epidemic of obesity and many other cardiometabolic problems or all of the related economic, health, and other consequences facing lowand middle-income countries, in particular. Effective action requires evidence-based, carefully evaluated programs and policies. This review summarizes a great deal of work that has occurred over the past half century in response to concerns about the rapid dietary shifts occurring in stages around the world.

\section{Acknowledgments}

R. Marten is thanked for his assistance in initiating and reviewing this document. Ms. Frances L. Dancy is thanked for administrative assistance, Mr. Tom Swasey for graphics support, and Dr. Phil Bardsley for programming assistance. Carlos Monteiro, Juan Rivera, Ricardo Uauy, and Srinath Reddy provided advice with selected components and are thanked.

Funding. This research was primarily funded by the Rockefeller Foundation. Additional support came from NIH grants R01-HD30880, DK056350, R24 HD050924, and R01-HD38700.

Declaration of interest. The authors have no relevant interests to declare.

\section{REFERENCES}

1. Popkin B, Drewnowski A. Dietary fats and the nutrition transition: new trends in the global diet. Nutr Rev. 1997;55: 31-43.

2. Popkin BM. The nutrition transition in low-income countries: an emerging crisis. Nutr Rev. 1994;52:285-298.
3. Kleiman S, Ng SW, Popkin BM. Drinking to our health: can beverage companies cut calories while maintaining profits? Obes Rev. In Press. doi: 10.1111/j.1467-789X.2011.00949.x.

4. Monteiro CA, Gomes FS, Cannon G. The snack attack. Am J Public Health. 2010;100:975-981.

5. Monteiro C. The big issue is ultra-processing. J World Pub Health Nutr Assoc. Available at: http://www.wphna.org/ wn_commentary_ultraprocessing_nov2010.asp.

6. Popkin BM. The World Is Fat - The Fads, Trends, Policies, and Products That Are Fattening the Human Race. New York, NY: Avery-Penguin Group; 2008.

7. Mourao D, Bressan J, Campbell W, Mattes R. Effects of food form on appetite and energy intake in lean and obese young adults. Int J Obes (Lond). 2007;31:1688-1695.

8. Mattes RD. Dietary compensation by humans for supplemental energy provided as ethanol or carbohydrate in fluids. Physiol Behav. 1996;59:179-187.

9. Drewnowski A. Sweetness and obesity. In: Dobbing J, ed. Sweetness. Berlin, Germany: Springer-Verlag; 1987:177192.

10. Blundell JE, Hill AJ. Paradoxical effects of an intense sweetener (aspartame) on appetite. Lancet. 1986;1:10921093.

11. Drewnowski A. Sensory preferences for fat and sugar in adolescence and adult life. Ann NY Acad Sci. 1989;561:243-250.

12. Malik VS, Popkin BM, Bray GA, Despres JP, Hu FB. Sugarsweetened beverages, obesity, type 2 diabetes mellitus, and cardiovascular disease risk. Circulation. 2010;121:13561364.

13. Kastorini CM, Milionis HJ, loannidi A, et al. Adherence to the Mediterranean diet in relation to acute coronary syndrome or stroke nonfatal events: a comparative analysis of a case/ case-control study. Am Heart J. 2011;162:717-724.

14. Nguyen TT, Adair LS, Suchindran CM, He K, Popkin BM. The association between body mass index and hypertension is different between East and Southeast Asians. Am J Clin Nutr. 2009;89:1905-1912.

15. WHO Expert Consultation. Appropriate body-mass index for Asian populations and its implications for policy and intervention strategies. Lancet. 2004;363:157-163.

16. Subramanian SV, Perkins JM, Özaltin E, Davey-Smith G. Weight of nations: a socioeconomic analysis of women in low- to middle-income countries. Am J Clin Nutr. 2011;93: 413-421.

17. Popkin BM, Conde W, Hou N, Monteiro C. Is there a lag globally in overweight trends for children compared with adults? Obesity (Silver Spring). 2006;14:1846-1853.

18. Monteiro CA, D'A Benicio MH, Conde WL, Popkin BM. Shifting obesity trends in Brazil. Eur J Clin Nutr. 2000;54: 342-346.

19. Jones-Smith JC, Gordon-Larsen P, Siddiqi A, Popkin BM. Emerging disparities in overweight by educational attainment in Chinese adults (1989-2006). Int J Obes (London). 2011; doi: 10.1038/ijo.2011.134. [Epub ahead of print]

20. Jones-Smith J, Gordon-Larsen P, Siddiqi A, Popkin B. Crossnational comparisons of time trends in overweight inequality by socioeconomic status among women using repeated cross-sectional surveys from 37 developing countries, 1989-2007. Am J Epidemiol. 2011;173:667-675.

21. Jones-Smith JC, Gordon-Larsen P, Siddiqi A, Popkin BM. Is the burden of overweight shifting to the poor across the globe? Time trends among women in 39 low- and middleincome countries (1991-2008). Int J Obes (London). 2011; doi: 10.1038/ijo.2011.179. [Epub ahead of print] 
22. Monteiro CA, Moura EC, Conde WL, Popkin BM. Socioeconomic status and obesity in adult populations of developing countries: a review. Bull World Health Organ. 2004;82:940946.

23. Bell AC, Ge K, Popkin BM. Weight gain and its predictors in Chinese adults. Int J Obes Relat Metab Disord. 2001;25: 1079-1086.

24. Bell AC, Ge K, Popkin BM. The road to obesity or the path to prevention: motorized transportation and obesity in China. Obes Res. 2002;10:277-283.

25. Monda KL, Adair LS, Zhai F, Popkin BM. Longitudinal relationships between occupational and domestic physical activity patterns and body weight in China. Eur J Clin Nutr. 2008;62:1318-1325.

26. Gluckman PD, Hanson M, Zimmet P, Forrester T. Losing the war against obesity: the need for a developmental perspective. Sci Transl Med. 2011;3:93cm19. doi: 10.1126/ scitranslmed.3002554.

27. Ng SW, Popkin BM. Time use and physical activity: a shift away from movement across the globe. Obes Rev. In Press.

28. Gluckman P, Hanson M, eds. Developmental Origins of Health and Disease. Cambridge, UK: Cambridge University Press; 2006.

29. Ravelli AC, van Der Meulen JH, Osmond C, Barker DJ, Bleker OP. Obesity at the age of 50 years in men and women exposed to famine prenatally. Am J Clin Nutr. 1999;70:811816.

30. Ravelli GP, Stein ZA, Susser MW. Obesity in young men after famine exposure in utero and early infancy. N Engl J Med. 1976;295:349-353.

31. Clarkin PF. Adiposity and height of adult Hmong refugees: relationship with war-related early malnutrition and later migration. Am J Hum Biol. 2008;20:174-184.

32. Rivera JA, Muñoz-Hernández 0 , Rosas-Peralta $M$, Aguilar-Salinas CA, Popkin BM, Willett WC. Consumo de bebidas para una vida saludable: recomendaciones para la población (Beverage consumption for a healthy life: recommendations for the Mexican population). Salud Publica Mex. 2008;50:173-195.

33. Popkin BM, Armstrong LE, Bray GM, Caballero B, Frei B, Willett WC. A new proposed guidance system for beverage consumption in the United States. Am J Clin Nutr. 2006;83:529-542.

34. Wolf A, Bray GA, Popkin BM. A short history of beverages and how our body treats them. Obes Rev. 2008;9:151-164.

35. Gluckman PD, Hanson MA, Bateson P, et al. Towards a new developmental synthesis: adaptive developmental plasticity and human disease. Lancet. 2009;373:1654-1657.

36. Puddu M, Fanos V, Podda F, Zaffanello M. The kidney from prenatal to adult life: perinatal programming and reduction of number of nephrons during development. Am J Nephrol. 2009;30:162-170.

37. Waterland RA. Early environmental effects on epigenetic regulation in humans. Epigenetics. 2009;4:523-525.

38. Waterland RA. Is epigenetics an important link between early life events and adult disease? Horm Res. 2009;71(Suppl 1):13-16

39. Yajnik CS, Deshpande SS, Jackson AA, et al. Vitamin $B_{12}$ and folate concentrations during pregnancy and insulin resistance in the offspring: the Pune Maternal Nutrition Study. Diabetologia. 2008;51:29-38.

40. Yajnik CS, Deshmukh US. Maternal nutrition, intrauterine programming and consequential risks in the offspring. Rev Endocr Metab Disord. 2008;9:203-211.
41. Joglekar CV, Fall CH, Deshpande VU, et al. Newborn size, infant and childhood growth, and body composition and cardiovascular disease risk factors at the age of 6 years: the Pune Maternal Nutrition Study. Int J Obes (Lond). 2007;31: 1534-1544.

42. Yajnik CS, Fall CH, Coyaji KJ, et al. Neonatal anthropometry: the thin-fat Indian baby. The Pune Maternal Nutrition Study. Int J Obes Relat Metab Disord. 2003;27:173-180.

43. Bush NC, Chandler-Laney PC, Rouse DJ, Granger WM, Oster RA, Gower BA. Higher maternal gestational glucose concentration is associated with lower offspring insulin sensitivity and altered beta-cell function. J Clin Endocrinol Metab. 2011;96:E803-E809.

44. Baptiste-Roberts K, Nicholson WK, Wang NY, Brancati FL. Gestational diabetes and subsequent growth patterns of offspring: The National Collaborative Perinatal Project. Matern Child Health J. 2011; doi: 10.007/s10995-0110756-2. [Epub ahead of print]

45. Fall $\mathrm{CH}$. Evidence for the intra-uterine programming of adiposity in later life. Ann Hum Biol. 2011;38:410-428.

46. Kramer MS. Determinants of low birth weight: methodological assessment and meta-analysis. Bull World Health Organ. 1987;65:663-737.

47. Widdowson EM. The response of the sexes to nutritional stress. Proc Nutr Soc. 1976;35:175-180.

48. Fernald LC, Neufeld LM. Overweight with concurrent stunting in very young children from rural Mexico: prevalence and associated factors. Eur J Clin Nutr. 2007;61:623-632.

49. Ong KK, Loos RJ. Rapid infancy weight gain and subsequent obesity: systematic reviews and hopeful suggestions. Acta Paediatr. 2006;95:904-908.

50. Adair LS, Martorell R, Stein AD, et al. Size at birth, weight gain in infancy and childhood, and adult blood pressure in 5 low- and middle-income-country cohorts: when does weight gain matter? Am J Clin Nutr. 2009;89:1383-1392.

51. Adair LS. Developing world perspective: the importance of growth for short-term health. Nestle Nutr Workshop Ser Pediatr Program. 2010;65:71-83.

52. Victora CG, Adair L, Fall C, et al. Maternal and child undernutrition: consequences for adult health and human capital. Lancet. 2008;371:340-357.

53. Victora CG, Barros FC. Commentary: the catch-up dilemma relevance of Leitch's "low-high" pig to child growth in developing countries. Int J Epidemiol. 2001;30:217-220.

54. Mendez MA, Adair LS. Severity and timing of stunting in the first two years of life affect performance on cognitive tests in late childhood. J Nutr. 1999;129:1555-1562.

55. Norris SA, Osmond C, Gigante D, Kuzawa CW, Ramakrishnan L, Lee NR, Ramirez-Zea M, Richter LM, Stein AD, Tandon N, Fall CH; and the COHORTS group. Size at birth, weight gain in infancy and childhood, and adult diabetes risk in five low- or middle-income country birth cohorts. Diabetes Care. 2011;Nov 18. [Epub ahead of print]

56. Owen CG, Martin RM, Whincup PH, Smith GD, Cook DG. Effect of infant feeding on the risk of obesity across the life course: a quantitative review of published evidence. Pediatrics. 2005; 115:1367-1377.

57. Horta B, Bahl R, Martinés J, Victora C. Evidence on the LongTerm Effects of Breastfeeding: Systematic Reviews and MetaAnalysis. Geneva, Switzerland: World Health Organization; 2007.

58. Kramer MS, Matush L, Vanilovich I, et al. Effects of prolonged and exclusive breastfeeding on child height, weight, adipos- 
ity, and blood pressure at age 6.5 years: evidence from a large randomized trial. Am J Clin Nutr. 2007;86:17171721.

59. Gunther AL, Remer T, Kroke A, Buyken AE. Early protein intake and later obesity risk: which protein sources at which time points throughout infancy and childhood are important for body mass index and body fat percentage at 7 years of age? Am J Clin Nutr. 2007;86:1765-1772.

60. Koletzko $B$, von Kries $R$, Closa R, et al. Can infant feeding choices modulate later obesity risk? Am J Clin Nutr. 2009;89(Suppl):S1502-S1508.

61. Hakanen M, Lagstrom H, Pahkala K, et al. Dietary and lifestyle counselling reduces the clustering of overweightrelated cardiometabolic risk factors in adolescents. Acta Paediatr. 2010;99:888-895.

62. Niinikoski $H$, Lagstrom $H$, Jokinen $E$, et al. Impact of repeated dietary counseling between infancy and 14 years of age on dietary intakes and serum lipids and lipoproteins: the STRIP study. Circulation. 2007;116:1032-1040.

63. Geleijnse JM, Hofman A, Witteman JC, Hazebroek AA, Valkenburg HA, Grobbee DE. Long-term effects of neonatal sodium restriction on blood pressure. Hypertension. 1997;29:913-917.

64. Popkin BM. Will China's nutrition transition overwhelm its health care system and slow economic growth? Health Aff (Millwood). 2008;27:1064-1076.

65. Popkin BM, Nielsen SJ. The sweetening of the world's diet. Obes Res. 2003;11:1325-1332.

66. Duffey KJ, Popkin BM. High-fructose corn syrup: is this what's for dinner? Am J Clin Nutr. 2008;88(Suppl):S1722S1732.

67. Rigola D, Pe ME, Fabrizio C, Me G, Sari-Gorla M. CaMADS1, a MADS box gene expressed in the carpel of hazelnut. Plant Mol Biol. 1998;38:1147-1160.

68. Reedy J, Krebs-Smith S. Dietary sources of energy, solid fats, and added sugars among children and adolescents in the United States. J Am Diet Assoc. 2010;110:14771484.

69. Barquera S, Campirano F, Bonvecchio A, Hernández L, Rivera J, Popkin B. Caloric beverage consumption patterns in Mexican children. Nutr J. 2010;9:47-56.

70. Barquera S, Hernández L, Tolentino ML, et al. Energy from beverages is on the rise among Mexican adolescents and adults. J Nutr. 2008;138:2454-2461.

71. Delgado CL. Rising consumption of meat and milk in developing countries has created a new food revolution. J Nutr. 2003;133(Suppl):S3907-S3910.

72. Du S, Mroz TA, Zhai F, Popkin BM. Rapid income growth adversely affects diet quality in China - particularly for the poor! Soc Sci Med. 2004;59:1505-1515.

73. Popkin BM, Du S. Dynamics of the nutrition transition toward the animal foods sector in China and its implications: a worried perspective. J Nutr. 2003;133(Suppl):S3898S3906.

74. Sinha R, Cross AJ, Graubard BI, Leitzmann MF, Schatzkin A. Meat intake and mortality: a prospective study of over half a million people. Arch Intern Med. 2009;169:562-571.

75. Food and Agricultural Organization of the United Nations. Livestock's Long Shadow: Environmental Issues and Options. Rome: Food and Agricultural Organization United Nations. 2007.

76. Popkin BM, Keyou G, Zhai F, Guo X, Ma H, Zohoori N. The nutrition transition in China: a cross-sectional analysis. Eur J Clin Nutr. 1993;47:333-346.
77. Du S, Lu B, Zhai F, Popkin BM. A new stage of the nutrition transition in China. Public Health Nutr. 2002;5:169-174.

78. Popkin BM, Siega-Riz AM, Haines PS. A comparison of dietary trends among racial and socioeconomic groups in the United States. N Engl J Med. 1996;335:716-720.

79. Popkin BM. Agricultural policies, food and public health. EMBO Rep. 2011;12:11-18.

80. Reardon T, Timmer CP, Barrett CB, Berdegue JA. The rise of supermarkets in Africa, Asia, and Latin America. Am J Agr Econ. 2003;85:1140-1146.

81. Asfaw A. Does consumption of processed foods explain disparities in the body weight of individuals? The case of Guatemala. Health Econ. 2011;20:184-195.

82. Monteiro CA. Nutrition and health. The issue is not food, nor nutrients, so much as processing. Public Health Nutr 2009;12:729-731.

83. Balsevich F, Berdegue JA, Flores L, Mainville D, Reardon T. Supermarkets and produce quality and safety standards in Latin America. Am J Agric Econ. 2003;85:1147-1154.

84. Popkin BM, Du S, Zhai F, Zhang B. Cohort Profile: The China Health and Nutrition Survey - monitoring and understanding socio-economic and health change in China, 19892011. Int J Epidemiol. 2009;39:1435-1440.

85. Kumar N, Quisumbing AR. Gendered Impacts of the 2007-08 Food Price Crisis: Evidence Using Panel Data from Rural Ethiopia. Washington, DC; 2011.

86. Griffiths $\mathrm{PL}$, Bentley ME. The nutrition transition is underway in India. J Nutr. 2001;131:2692-2700.

87. Doak CM, Adair LS, Bentley M, Monteiro C, Popkin BM. The dual burden household and the nutrition transition paradox. Int J Obes. 2005;29:129-136.

88. Doak CM, Adair LS, Monteiro C, Popkin BM. Overweight and underweight coexist within households in Brazil, China and Russia. J Nutr. 2000;130:2965-2971.

89. Garrett J, Ruel MT. The coexistence of child undernutrition and maternal overweight: prevalence, hypotheses, and programme and policy implications. Matern Child Nutr. 2005; 1:185-196.

90. Ramachandran P. Maternal \& child nutrition: new dimensions of the dual nutrition burden. Indian J Med Res. 2009; 130:575-578.

91. Jing J, ed. Feeding China's Little Emperors: Food, Children, and Social Change. Stanford, CA: Stanford University Press; 2000.

92. Dearth-Wesley T, Gordon-Larsen P, Adair LS, Siega-Riz AM, Zhang B, Popkin BM. Less traditional diets in Chinese mothers and children are similarly linked to socioeconomic and cohort factors but vary with increasing child age. J Nutr. 2011;141:1705-1711.

93. Fernald LC, Gertler PJ, Hou X. Cash component of conditional cash transfer program is associated with higher body mass index and blood pressure in adults. J Nutr. 2008; 138:2250-2257.

94. Fernald LC, Gertler PJ, Neufeld LM. 10-year effect of Oportunidades, Mexico's conditional cash transfer programme, on child growth, cognition, language, and behaviour: a longitudinal follow-up study. Lancet. 2009;374:1997-2005.

95. Uauy R, Kain J. The epidemiological transition: need to incorporate obesity prevention into nutrition programmes. Public Health Nutr. 2002;5:223-229.

96. Schultz T. Transforming Traditional Agriculture. New Haven, CT: Yale University Press; 1964.

97. Griliches Z. Estimating the returns to schooling: some econometric problems. Econometrica. 1977;45:1-22. 
98. Coitinho D, Monteiro CA, Popkin BM. What Brazil is doing to promote healthy diets and active lifestyles. Public Health Nutr. 2002;5:263-267.

99. Heller PS, Drake WD. Malnutrition, child morbidity and the family decision process. J Dev Economics. 1979;6(2):203235.

100. Roodenburg A, Popkin B, Seidell J. Development of international criteria for a front of package nutrient profiling system: International Choices Programme. Eur J Clin Nutr. 2011;65:1190-1200.

101. Wartella EA, Lichtenstein AH, Boon CS, eds. Examination of Front-of-Package Nutrition Rating Systems and Symbols: Phase 1 Report. Washington DC: National Academy Press; 2010.

102. Food and Nutrition Board. Front-of-Package Nutrition Rating Systems and Symbols: Promoting Healthier Choices. Washington, DC: National Academy Press; 2011.

103. Ludwig DS. Technology, diet, and the burden of chronic disease. JAMA. 2011;305:1352-1353.

104. Frazao E. America's Eating Habits: Changes and Consequences. Washington, DC: USDA; 1999.

105. Muckelbauer R, Libuda L, Clausen K, Toschke AM, Reinehr T, Kersting M. Promotion and provision of drinking water in schools for overweight prevention: randomized, controlled cluster trial. Pediatrics. 2009;123:e661-e667.

106. Rivera JA, Barquera S, Campirano F, Campos I, Safdie M, Tovar V. Epidemiological and nutritional transition in Mexico: rapid increase of non-communicable chronic diseases and obesity. Public Health Nutr. 2002;5:113122.

107. Rivera JA, Barquera S, Gonzalez-Cossio T, Olaiz G, Sepulveda J. Nutrition transition in Mexico and in other Latin American countries. Nutr Rev. 2004;62(Suppl):S149S157.

108. Barquera S, Peterson KE, Must A, et al. Coexistence of maternal central adiposity and child stunting in Mexico. Int J Obes. 2007;31:601-607.

109. Kain J, Leyton B, Cerda R, Vio F, Uauy R. Two-year controlled effectiveness trial of a school-based intervention to prevent obesity in Chilean children. Public Health Nutr. 2009;12: 1451-1461.

110. Brownell KD, Horgen KB. Food Fight: The Inside Story of the Food Industry, America's Obesity Crisis, and What We Can Do About It. New York, NY: McGraw-Hill; 2003.

111. Nestle M. Soft drink "pouring rights": marketing empty calories to children. Public Health Rep. 2000;115:308-319.

112. United Nations Subcommittee for Coordinating Nutrition. Scaling Up Nutrition (SUN). 2009; Available at: http:// www.unscn.org/files/Announcements/Scaling_Up_ Nutrition-A_Framework_for_Action.pdf. Accessed 25 September 2011.

113. Krishnaveni GV, Hill JC, Veena SR, et al. Low plasma vitamin $B_{12}$ in pregnancy is associated with gestational "diabesity" and later diabetes. Diabetologia. 2009;52:2350-2358.

114. Kimani-Murage EW, Kahn K, Pettifor JM, Tollman SM, Klipstein-Grobusch K, Norris SA. Predictors of adolescent weight status and central obesity in rural South Africa. Public Health Nutr. 2011;14:1114-1122.

115. Koletzko $B$, von Kries $\mathrm{R}$, Monasterolo RC, et al. Infant feeding and later obesity risk. Adv Exp Med Biol. 2009; 646:15-29.

116. Singhal A, Kennedy K, Lanigan J, et al. Nutrition in infancy and long-term risk of obesity: evidence from 2 randomized controlled trials. Am J Clin Nutr. 2010;92:1133-1144.
117. Hakanen M, Lagstrom H, Kaitosaari T, et al. Development of overweight in an atherosclerosis prevention trial starting in early childhood. The STRIP study. Int J Obes (Lond). 2006; 30:618-626.

118. Duran P, Caballero B, de Onis M. The association between stunting and overweight in Latin American and Caribbean preschool children. Food Nutr Bull. 2006;27: 300-305.

119. Uauy R, Kain J, Corvalan C. How can the developmental origins of health and disease ( $\mathrm{DOHaD}$ ) hypothesis contribute to improving health in developing countries? Am J Clin Nutr. 2011;doi: 10.3945/ajcn.110.000562.[Epub ahead of print]

120. Alston JM, Pardey PG. Public funding for research into specialty crops. HortScience. 2008;43:1461-1470.

121. Alston JM, Sumner DA, Vosti SA. Are agricultural policies making us fat? likely links between agricultural policies and human nutrition and obesity, and their policy implications. Rev Agric Econ. 2006;28:313-322.

122. Brownell KD, Farley T, Willett WC, et al. The public health and economic benefits of taxing sugar-sweetened beverages. N Engl J Med. 2009;361:1599-1605.

123. Duffey KJ, Gordon-Larsen P, Shikany JM, Guilkey D, Jacobs DR Jr, Popkin BM. Food price and diet and health outcomes: 20 years of the CARDIA study. Arch Intern Med. 2010;170:420-426.

124. Ng SW, Mhurchu CN, Jebb SA, Popkin BM. Patterns and trends of beverage consumption among children and adults in Great Britain, 1986-2009. Br J Nutr. In Press.

125. Duffey KJ, Huybrechts I, Mouratidou T, et al. Beverage consumption among European adolescents in the HELENA study. Eur J Clin Nutr. 2011;doi: 10.1038/ejcn.2011.166. [Epub ahead of print]

126. Pollan M. The Omnivore's Dilemma: A Natural History of Four Meals. New York: Penguin Press HC; 2006.

127. Brownell KD, Warner KE. The perils of ignoring history: Big Tobacco played dirty and millions died. How similar is Big Food? Milbank Q. 2009;87:259-294.

128. Warner KE. Tobacco policy in the United States: lessons for the obesity epidemic. In: Mechanic D, Rogut LB, Colby DC, Knickman JR, eds. Policy Challenges in Modern Health Care. New Brunswick, NJ: Rutgers University Press; 2005: 99-114.

129. Nestle M. Food Politics: How the Food Industry Influences Nutrition and Health, 2nd ed. Berkeley, CA: University of California Press; 2007.

130. Hawkes C, Lobstein T. Regulating the commercial promotion of food to children: a survey of actions worldwide. Int J Pediatr Obes. 2011;6:83-94.

131. Committee on Food Marketing and the Diets of Children and Youth. Food Marketing to Children and Youth: Threat Or Opportunity? Washington, DC: National Academies Press; 2005.

132. Watson JL. Golden Arches East: McDonald's in East Asia. Stanford, CA: Stanford University Press; 1997.

133. Fernald LC, Adler NE. Blood pressure and socioeconomic status in low-income women in Mexico: a reverse gradient? J Epidemiol Community Health. 2008;62:e8.

134. Wang Z, Zhai F, Du S, Popkin B. Dynamic shifts in Chinese eating behaviors. Asia Pac J Clin Nutr. 2008;17: 123-130.

135. Popkin B. What's wrong with the U.S. approach to obesity? Virtual Mentor. 2010;12:316-320. Available at: http:// virtualmentor.ama-assn.org/2010/04/pfor2-1004.html. 
136. King D. Foresight report on obesity [Letter to the editor]. Lancet. 2007;370:1754; author reply 1755.

137. Kopelman P. Symposium 1: Overnutrition: consequences and solutions. Foresight Report: the obesity challenge ahead. Proc Nutr Soc. 2010;69:80-85.

138. McPherson K, Marsh T, Brown M. Foresight report on obesity[Letter to the editor]. Lancet. 2007;370:1755; author reply 1755.

139. Kim S, Moon S, Popkin BM. The nutrition transition in South Korea. Am J Clin Nutr. 2000;71:44-53.

140. Lee MJ, Popkin BM, Kim S. The unique aspects of the nutrition transition in South Korea: the retention of healthful elements in their traditional diet. Public Health Nutr. 2002; 5:197-203.

141. Moll-Weiss A. De la meilleure utilisation du salaire familial. L'Art ménager. 1930;42:261.

142. Moll-Weiss A. Le Foyer Domestique cours d'économie domestique d'hygiène et de cuisine pratique professé à l'école des mères de Bordeaux.

143. Popkin BM. Technology, transport, globalization and the nutrition transition. Food Policy. 2006;31:554-569.

144. Chaloupka FJ, Cummings KM, Morley CP, Horan JK. Tax, price and cigarette smoking: evidence from the tobacco documents and implications for tobacco company marketing strategies. Tob Control. 2002;11(Suppl 1):162-I72.

145. Liang L, Chaloupka F, Nichter M, Clayton R. Prices, policies and youth smoking, May 2001. Addiction. 2003;98(Suppl 1):105-122.

\section{SUPPORTING INFORMATION}

Additional Supporting Information may be found in the online version of this article:

Figure S1. Absolute and relative annual percentage point change in weighted prevalence of obesity $(\mathrm{BMI} \geq 30)$ among women in rural and urban areas of 42 countries by region $(\mathrm{N}=42)$.

Figure S2. Prevalence of overweight and obesity among women aged 18-49 years ranked by gross domestic product per capita in 2009 US dollars $(\mathrm{N}=42)$.

Figure S3. Trends in global prices for beef in 1990 US Dollars.

Figure S4. Real prices of selected food items in China, 1991-2004.

Table S1. Global rates and trends among women aged $18-49$ years who are overweight or obese (BMI $\geq 25$ ), age standardized.

Please note: Wiley-Blackwell are not responsible for the content or functionality of any supporting materials supplied by the authors. Any queries (other than missing material) should be directed to the corresponding author for the article. 